\title{
Characteristics, prevalence, and prognosis of postmyocardial infarction syndrome
}

\author{
LENNART WELIN, ANDERS VEDIN, CLAES WILHELMSSON \\ From the Department of Medicine, University of Göteborg, Ostra Hospital, Göteborg, Sweden
}

SUMMARY Among 1809 patients with myocardial infarction, 60 (3.3\%) later developed a postmyocardial infarction syndrome. These 60 patients were compared with controls with myocardial infarction but without postmyocardial infarction syndrome. Cases with postmyocardial infarction syndrome had larger and more complicated infarcts than control subjects. Five year cumulative mortality was higher among cases $(26 \%)$ than among control subjects $(18 \%)$ but this difference was not statistically significant. Corticosteroid treatment did not adversely affect the prognosis of the postmyocardial infarction syndrome, which we conclude is mainly determined by the severity of the underlying coronary heart disease.

The postmyocardial infarction syndrome was first described in 1955 by Dressler. ${ }^{1}$ It is characterised by pleuropericardial pain, fever, and a high erythrocyte sedimentation rate occurring weeks or months after a myocardial infarction. The prevalence varies from 0 to $4.6 \%$ of cases with myocardial infarction in different studies. ${ }^{2-7}$ Dressler ${ }^{6}$ concluded that on the whole it was a benign but annoying complication. To the best of our knowledge, however, no studies have been published comparing the prognosis of patients with postmyocardial infarction syndrome with that of patients with myocardial infarction without it.

The purpose of the present study was to establish this in a non-selected large group of patients with myocardial infarction.

\section{Patients and methods}

Since 1 January 1968, all cases of myocardial infarction in Göteborg have been registered by the special myocardial infarction register. ${ }^{8}$ The present study comprises patients who have been eligible for followup at a special postmyocardial infarction clinic. ${ }^{9}$ Their upper age limit was 55 years during 1968 to 1969,67 years in 1970 to 1971, 65 years in 1972, and since 1973 59 years. Until the end of 1977 a total of 1809 patients had survived their stay in hospital and were eligible and registered for follow-up at the postmyocardial infarction clinic. The myocardial infarction which led to registration is hereafter called the index myocardial infarction. All cases were followed up until the end of 1978.

Before discharge from hospital and at the first appointment at the postmyocardial infarction clinic all patients were interviewed with respect to symptoms and case history. Using special forms to ensure the uniform collection of data ${ }^{9}$ information about hypertension, angina pectoris, and smoking habits before and after the myocardial infarction was collected.

Findings during the hospital stay for the index myocardial infarction were also recorded on special forms. Left ventricular failure was considered to be present when more than occasional basal pulmonary râles and/or increased prominence of pulmonary vessels on $x$-ray film were recorded. Episodes of ventricular tachycardia or ventricular fibrillation were also recorded. Maximum enzyme levels were noted for serum aspartate aminotransferase (AST) which was determined once daily for a minimum of three days. Before discharge from hospital a chest $x$-ray film was done and the heart volume was calculated as described by Jonsell. ${ }^{10}$ These factors have earlier been found to be of prognostic importance. ${ }^{11}$

Patients with the postmyocardial infarction syndrome were diagnosed from available data collected both during the hospital stay and at the postmyocardial infarction clinic. Criteria for a definite diagnosis of postmyocardial infarction syndrome were: (1) pleuropericardial pain, (2) fever $\left(>37.5^{\circ} \mathrm{C}\right)$, and (3) a high erythrocyte sedimentation rate $(>40$ $\mathrm{mm}$ ) if these developed more than a week after the 
myocardial infarction. If only two of these three symptoms and signs were present the patient was considered to have a probable postmyocardial infarction syndrome. In all cases other diseases capable of causing these symptoms and signs had to be excluded before the case was accepted. Thus, reinfarction, venous thrombosis, pulmonary embolism, heart failure, various infections such as bronchopneumonia and those of the urinary tract, and collagen and malignant diseases had to be ruled out.

During follow-up the patients were seen regularly at the postmyocardial infarction clinic, on average every sixth week during the first year of follow-up. Thereafter they were seen as often as was deemed necessary from a clinical standpoint but always at two and five years after the index myocardial infarction. Standardised criteria were used for institution of treatment, for instance digitalis and diuretics. The patients were attended by a small team of physicians and the methods were continuously checked to avoid intra- and interobserver variations. ${ }^{9}$

In order to establish the prognostic contribution of a diagnosis of postmyocardial infarction syndrome, two different matching procedures were applied. Matched controls were chosen consecutively from the files having their index myocardial infarction after the myocardial infarction of the case. In the first match two control subjects for each case with postmyocardial infarction syndrome were chosen, and the matching factors were age, sex, and the interval between the index myocardial infarction and the development of the postmyocardial infarction syndrome. Since the latter can only be diagnosed in life, often months after myocardial infarction, and since the mortality rate after infarction is highest during the first months, this interval must be used when matching control subjects or the data will be biased prognostically in favour of the patients with the post-myocardial infarction syndrome.

The second match was made for secondary risk factors, namely maximum enzyme rise (AST) and left ventricular failure during the index myocardial infarction (severity matched controls). These factors are an approximate estimate of infarct size. Age, sex, and the interval between the infarction and the occurrence of the postmyocardial infarction syndrome as in the first match were also included as matching criteria and again two control subjects were chosen for each case. This match was made in order to obtain a more precise estimate of the prognostic importance of the postmyocardial infarction syndrome. Thirty-four control subjects in the first match were also included in the second.

STATISTICAL ANALYSES

$\chi^{2}$ tests were used for testing differences between qualitative variables. Differences between means of quantitative variables were determined using Student's t test. Life tables were constructed according to Cutler and Ederer ${ }^{12}$ using the standard error as described.

\section{Results}

Of the registered 1809 patients, 60 (3.3\%) developed the postmyocardial infarction syndrome within one year after their index myocardial infarction. Thirtynine $(65 \%)$ of the 60 developed it within three months and the others three to 12 months afterwards. Thirtyfour $(1.9 \%)$ had the postmyocardial infarction syndrome definitely and $26(1.4 \%)$ probably. There were 45 men $(75 \%)$. Men also contributed $75 \%$ of both groups of matched control subjects.

Patients with both definite and probable postmyocardial infarction syndrome did not differ with respect to maximum AST rise, heart volume, or left ventricular failure.

Thirty-six (60\%) of the patients with the postmyocardial infarction syndrome were treated with corticosteroids, eight of these for one year or more. There were significantly more patients classified as having a definite rather than a probable postmyocardial infarction syndrome among those receiving steriods ( $91 \%$ versus $19 \%)$. In all patients the response to steroid treatment was prompt, with relief of pain and return of body temperature to normal. No major complications (such as cardiac tamponade) occurred among patients with the postmyocardial infarction syndrome.

Table 1 shows that both groups of control subjects were matched accurately with respect to age. Tables 1 and 2 show that the severity matched control subjects had similar AST maximum rise and the same frequency of left ventricular failure as those with the postmyocardial infarction syndrome. Patients who developed this within three months $(65 \%)$ were matched with control subjects (65\% in each group) who survived for three months. The other $35 \%$ of patients were matched to $35 \%$ in each control group who survived one year.

All 60 patients with postmyocardial infarction syndrome were compared with the two groups of matched control subjects. Table 3 shows certain characteristics before and after the index myocardial infarction. Patients with the postmyocardial infarction syndrome had had a myocardial infarction more often than either group of control subjects. There were no differences in the frequency of angina pectoris and hypertension before the index myocardial infarction and smoking habits before and after it were similar.

Tables 1 and 2 show characteristics of prognostic 
Table 1 Age, maximum serum ensyme levels, and relative heart volume during hospital stay for index myocardial infarction

\begin{tabular}{|c|c|c|c|c|c|c|}
\hline & \multicolumn{2}{|c|}{ Postmyocardial infarction syndrome cases } & \multicolumn{2}{|c|}{$\begin{array}{l}\text { First group of controls } \\
(n=120)\end{array}$} & \multicolumn{2}{|c|}{$\begin{array}{l}\text { Severity matched controls } \\
(n=120)\end{array}$} \\
\hline & Mean & $S D$ & Mean & $S D$ & Mean & $S D$ \\
\hline $\begin{array}{l}\text { Age (y) } \\
\text { Maximum AST (ukat/l) } \\
\text { Relative heart volume }\end{array}$ & $\begin{array}{r}54.9 \\
4 \cdot 5 \\
528\end{array}$ & $\begin{array}{r}7 \cdot 1 \\
3 \cdot 4 \\
150\end{array}$ & $\begin{array}{l}54.8 \\
2.6 \ldots \star \\
457^{\star \star \star}\end{array}$ & $\begin{array}{l}6.9 \\
2.4 \\
88\end{array}$ & $\begin{array}{r}54 \cdot 9 \\
4 \cdot 1 \\
483^{\star}\end{array}$ & $\begin{array}{l}7 \cdot 0 \\
3 \cdot 1 \\
103\end{array}$ \\
\hline
\end{tabular}

${ }^{\star} \mathrm{p}<0.05$ compared with cases;

* $\mathrm{p}<0.01$ compared with cases;

$\star \star \star \mathrm{p}<0.001$ compared with cases.

Note: The first group of control subjects were matched for age, sex, and survival until diagnosis of postmyocardial infarction syndrome. The severity matched control subjects were in addition matched for maximum AST rise and left ventricular failure during the index myocardial infarction.

Table 2 Characteristics of long term prognostic importance for index myocardial infarction (same two control groups as in Table 1)

\begin{tabular}{|c|c|c|c|c|c|c|}
\hline & \multicolumn{2}{|c|}{$\begin{array}{l}\text { Postmyocardial infarction } \\
\text { syndrome cases }(n=60)\end{array}$} & \multicolumn{2}{|c|}{$\begin{array}{l}\text { First group of control } \\
\text { subjects }(n=120)\end{array}$} & \multicolumn{2}{|c|}{$\begin{array}{l}\text { Severity matched control } \\
\text { subjects }(n=120)\end{array}$} \\
\hline & No. & $\%$ & No. & $\%$ & No. & $\%$ \\
\hline \multirow{3}{*}{$\begin{array}{l}\text { Dyspnoea at onset of index myocardial infarction } \\
\text { Ventricular tachycardia and/or fibrillation } \\
\text { during index myocardial infarction } \\
\text { Left ventricular failure during index myocardial } \\
\text { infarction }\end{array}$} & 18 & 30 & 39 & 33 & 46 & 38 \\
\hline & 8 & 13 & 5 & $4^{\star}$ & 9 & 8 \\
\hline & 33 & 55 & 18 & $15^{\star \star \star}$ & 63 & 53 \\
\hline
\end{tabular}

${ }^{\star} \mathrm{p}<0.05$ compared with cases;

$\star \star \star \mathrm{p}<0.001$ compared with cases.

Table 3 Characteristics before and after index myocardial infarction (same two control groups as in Table 1)

\begin{tabular}{|c|c|c|c|c|c|c|}
\hline & \multicolumn{2}{|c|}{$\begin{array}{l}\text { Postmyocardial infarction } \\
\text { syndrome cases }(n=60)\end{array}$} & \multicolumn{2}{|c|}{$\begin{array}{l}\text { First group of control } \\
\text { subjects }(n=120)\end{array}$} & \multicolumn{2}{|c|}{$\begin{array}{l}\text { Severity matched control } \\
\text { subjects }(n=120)\end{array}$} \\
\hline & No. & $\%$ & No. & $\%$ & No. & $\%$ \\
\hline \multirow{4}{*}{$\begin{array}{l}\text { Myocardial infarction before index myocardial } \\
\text { infarction } \\
\text { Angina pectoris before index myocardial } \\
\text { infarction } \\
\text { Smokers before index myocardial infarction } \\
\text { Smokers three months after index myocardial } \\
\text { infarction } \\
\text { Hypertension before index myocardial } \\
\text { infarction }\end{array}$} & 13 & 22 & 12 & $10^{\star}$ & 10 & $8^{\star}$ \\
\hline & $\begin{array}{l}14 \\
39\end{array}$ & $\begin{array}{l}23 \\
65\end{array}$ & $\begin{array}{l}24 \\
83\end{array}$ & $\begin{array}{l}20 \\
69\end{array}$ & $\begin{array}{l}29 \\
81\end{array}$ & $\begin{array}{l}24 \\
68\end{array}$ \\
\hline & 14 & 23 & 28 & 23 & 25 & 21 \\
\hline & 21 & 35 & 32 & 27 & 34 & 28 \\
\hline
\end{tabular}

${ }^{\star} \mathrm{p}<0.05$ compared with cases.

importance during the hospital stay for the index myocardial infarction. Cases later developing the postmyocardial infarction syndrome had significantly larger infarcts measured both as maximum rise in AST and relative heart volume than did control subjects of the first match. They also had infarcts more often complicated by left ventricular failure and serious ventricular arrhythmias.

The follow-up for cases and age and sex matched control subjects ranged from one and a half to 11 years. Fourteen patients and 30 subjects of both control groups had been followed for less than five years. Fourteen patients and 20 control subjects of the first group died within five years of follow-up. Fig. 1 illustrates the cumulative five year mortality, which was $26 \%$ among patients and $18 \%$ among control subjects of the first match, a non-significant difference. Nonfatal reinfarctions during the same follow-up time were $23 \%$ in the cases and $22 \%$ in the control subjects. Steroid treated and non-steroid treated patients with the postmyocardial infarction syndrome had similar five year cumulative mortality rates $(26 \%$ versus $23 \%$ ). (By "cumulative mortality" we mean an actuarial calculation of the mortality of each year of followup separately on the basis only of the patients followed throughout that year or until earlier death. ${ }^{12}$ ) The controls matched for severity had a five year cumulative mortality of $29 \%$ (Fig. 2). This is again not significantly different from the mortality among patients with the postmyocardial infarction syndrome. In this group 32 control subjects had died within five years of follow-up. 


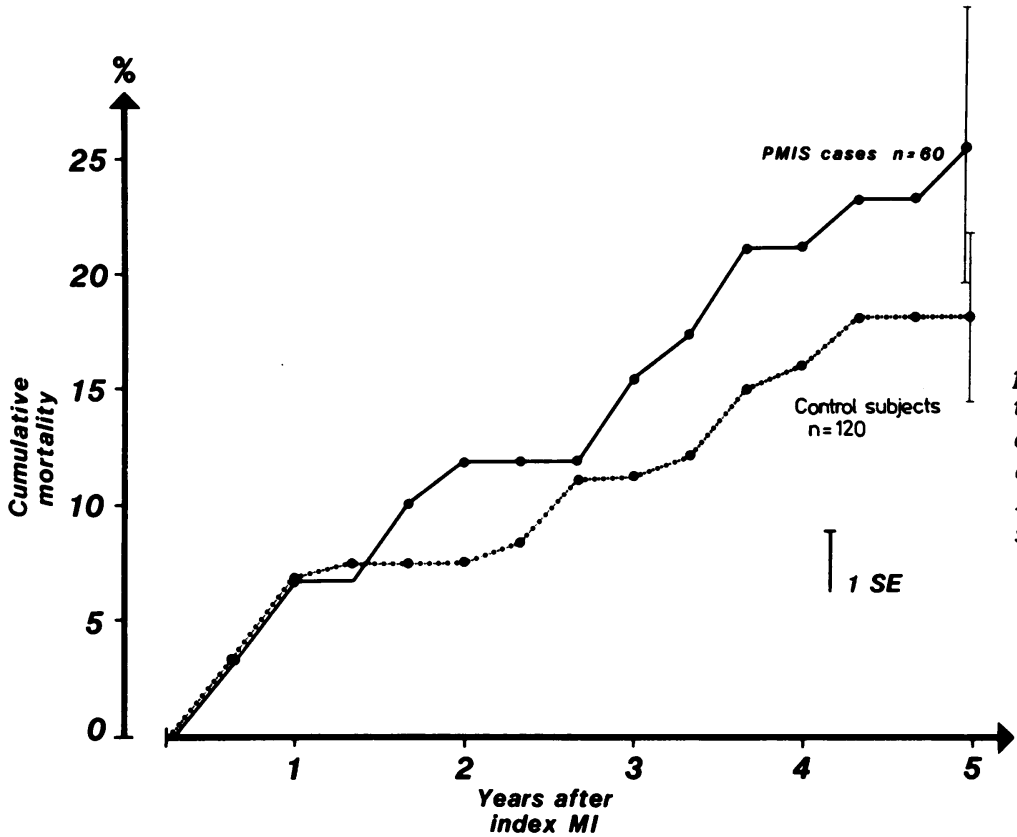

Fig. 1 Cumulative mortality among patients with postmyocardial infarction syndrome (PMIS) and control subjects matched for age, sex, and survival time until diagnosis of PMIS (the first group of control subjects).

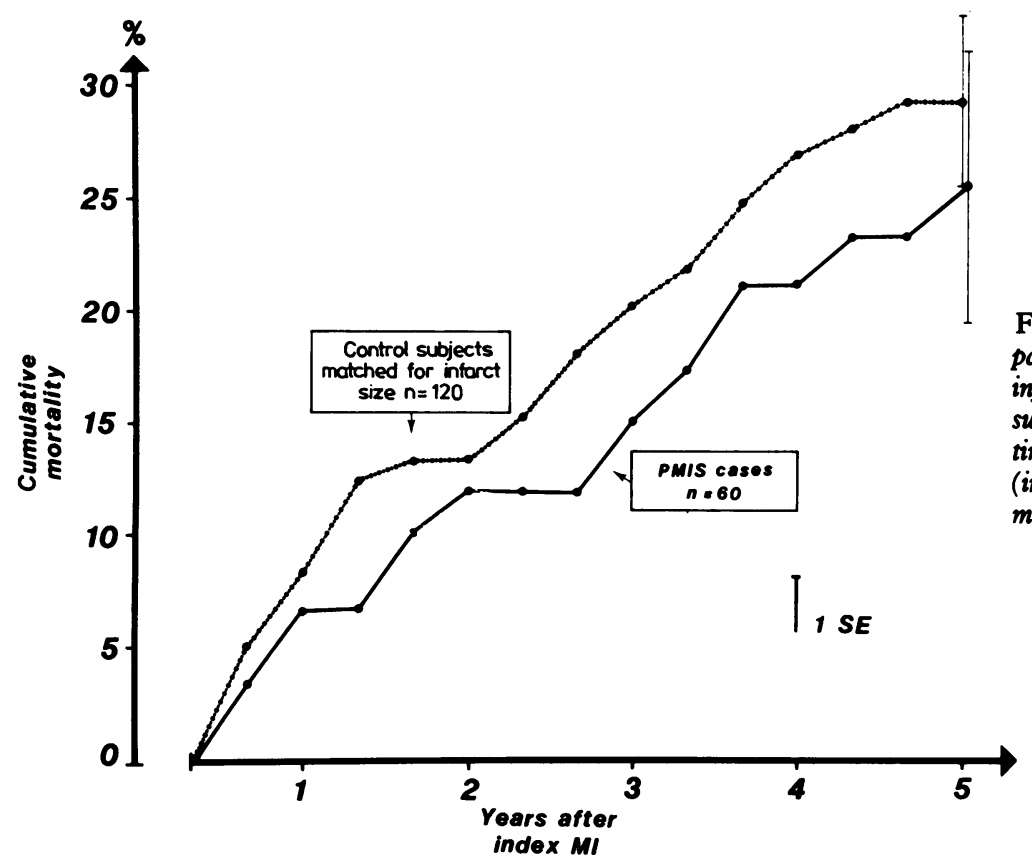

Fig. 2 Cumulative mortality among patients with postmyocardial infarction syndrome and control subjects matched for age, sex, survival time, and secondary risk factors (infarct size, that is the severity matched control subjects).

\section{Discussion}

The prevalence of the postmyocardial infarction syndrome in our population with myocardial infarction was $3.3 \%$ which is in agreement with the findings of
Markoff ${ }^{5}$ and Dressler ${ }^{6}$ but higher than that found by others. ${ }^{2-4}$

The upper age limit for patients followed up at the postmyocardial infarction clinic has been 59 years for seven of the 10 years from which we present our data. 
Therefore the prevalence of the postmyocardial infarction syndrome among elderly patients with myocardial infarction is not known. The drop-out rate from the postmyocardial infarction clinic for reasons other than death was only $3 \%$ in the first two years ${ }^{9}$ and we therefore believe that few if any patients with the postmyocardial infarction syndrome have been missed in the age groups studied. During the first year after their myocardial infarction, our patients also have frequent visits both from physicians and nurses from the postmyocardial infarction clinic which should have lessened the risk of missing mild cases. The postmyocardial infarction syndrome after silent myocardial infarction or pacemaker implantation has been reported. 1314 The number of such cases is not known to us since a myocardial infarction producing symptoms was required for registration and followup.

To diagnose the postmyocardial infarction syndrome we have adopted criteria proposed by others ${ }^{67}$ with some simplification but with emphasis on excluding other conditions mimicking the syndrome. There still remains, of course, the possibility that the syndrome may have been diagnosed too frequently.

Since patients with the postmyocardial infarction syndrome had larger and more complicated infarcts they should have a poorer prognosis than other patients with myocardial infarction. ${ }^{11}$ We did not, however, find any significant differences in five year mortality between our cases and the two groups of control subjects. Matching for survival until the diagnosis of the postmyocardial infarction syndrome has probably abolished part of the expected difference between the cases and the first group of control subjects matched only for age and sex. This interval includes the critical first weeks and months after a myocardial infarction when the mortality is still high, especially among those with large infarcts. Corticosteroid treatment did not adversely affect the prognosis in our patients though others ${ }^{15}$ have argued against its use in the postmyocardial infarction syndrome because of the increased risk of developing large ventricular aneurysms.

Immunological mechanisms have been implicated in the development of the postmyocardial infarction syndrome. ${ }^{6}$ This has been supported by reports that antibodies to different myocardial antigens have been found more frequently among cases with the syndrome than among those without it. ${ }^{16-20}$ Recently, Trueman and co-workers ${ }^{21}$ have described a consistent, positive immunofluorescent staining pattern in a few patients with the postmyocardial infarction syndrome. Their method needs confirmation and might in the future be helpful in diagnosing the syndrome without embarking on complicated and time consuming differential diagnostic procedures. We have so far not performed systematic immunological studies in our patients.

In summary, the prognosis of the postmyocardial infarction syndrome is influenced by the prognosis of the underlying myocardial infarction and not by the severity of the syndrome itself or by corticosteroid treatment.

This study was supported by grants from the Medical Society of Göteborg and the Swedish Association against Heart and Chest Diseases. We are also grateful to Dr Anders Odén for statistical advice.

\section{References}

1 Dressler W. A complication of myocardial infarction resembling idiopathic, recurrent benign pericarditis [Abstract]. Circulation 1955; 12: 697.

2 Liem KL, ten Veen JH, Lie KI, Feltkamp TEW, Durrer D. Incidence and significance of heart muscle antibodies in patients with acute myocardial infarction and unstable angina. Acta Med Scand 1979; 206: 473-5.

3 Broch OJ, Ofstad J. The post-myocardial-infarction syndrome. Acta Med Scand 1960; 166: 281-90.

4 Davidson C, Oliver MF, Robertson RF. Postmyocardial-infarction syndrome. $B r$ Med $\mathcal{f}$ 1961; ii: 535-9.

5 Markoff R. Klinische Bedeutung des DresslerSyndroms. Dtsch Med Wochenschr 1968; 93: 627-33.

6 Dressler $W$. The post-myocardial-infarction syndrome. Arch Intern Med 1959; 103: 28-42.

7 Samaras C, Kolettis M, Papaconstantinu C. The postmyocardial infarction syndrome. Dis Chest 1961; 40: 330-7.

8 Elmfeldt D, Wilhelmsen L, Tibblin G, Vedin JA, Wilhelmsson CE, Bengtsson C. Registration of myocardial infarction in the city of Göteborg, Sweden. $\mathcal{F}$ Chronic Dis 1975; 28: 173-86.

9 Elmfeldt D, Wilhelmsen L, Tibblin G, Vedin JA, Wilhelmsson CE, Bengtsson C. A postmyocardial infarction clinic in Göteborg, Sweden. Acta Med Scand 1975; 197: 497-502.

10 Jonsell S. A method for the determination of the heart size by teleroentgenography (a heart volume index). Acta Radiologica 1939; 20: 325-40.

11 Vedin A, Wilhelmsen L, Wedel $\mathrm{H}$, et al. Prediction of cardiovascular deaths and non-fatal reinfarctions after myocardial infarction. Acta Med Scand 1977; 201: 309 16.

12 Cutler SJ, Ederer F. Maximum utilization of the life table method in analyzing survival. $\mathcal{F}$ Chronic Dis 1958; 8: 699-712.

13 Dressler W, August S, Epstein I, Rosenberg B. Pericarditis following mild or silent coronary episodes: an attempt at narrowing the field of idiopathic pericarditis. Am Heart $\mathcal{F}$ 1960; 60: 721-8.

14 Dressler W. Postcardiotomy syndrome after implantation of a pacemaker. Am Heart $\mathcal{F}$ 1962; 63: 757-9.

15 Bulkley BH, Roberts WC. Steroid therapy during acute myocardial infarction. A cause of delayed healing and of ventricular aneurysm. Am $\mathcal{F}$ Med 1974; 56: 244-50. 
16 van der Geld H. Anti-heart antibodies in the postpericardiotomy and the post-myocardial-infarction syndromes. Lancet 1964; ii: 617-21.

17 Itoh $\mathrm{K}$, Ohkuni $\mathrm{H}$, Kimura E, Kimura $\mathrm{Y}$. Immunoserological studies on myocardial infarction and postmyocardial infarction syndrome. Fpn Heart $\mathcal{F} 1969$; 10: 485-502.

18 Kuch J, Chorzelski T. Immunofluorescence studies in recent myocardial infarction. Cardiovasc Res 1971; 5: 353-7.

19 Stahl D, Thyme S, Wanscher B. Sen febril tilstand efter akut myokardieinfarkt med specielt henblik på postmyokardieinfarktsyndromet (PMIS) og forekomsten af myokardieautoantistoffer. Ugeskr Laeger 1975; 137: 2709-14.

20 Maisch B, Berg PA, Kochsiek K. Immunologische differenzierung der Perikarditis nach Myokardinfarkt. Intensivmedizin 1979; 16: 28-32.

21 Trueman T, Thompson RA, Cummins P, Littler WA. Heart antibodies in cardiomyopathies. Br Heart $\mathcal{F} 1981$; 46: 296-301.

Requests for reprints to Dr Lennart Welin, Department of Medicine, Östra Hospital, S-416 85 Göteborg, Sweden 